\title{
Stabilization of Crude Oil Contaminated Soils with Alkali-Activated Slag
}

\author{
Hossein Sadighi, Mohammad Ali Rowshanzamir \\ Department of Civil Engineering, Isfahan University of Technology, Isfahan, Iran \\ E-mail: h.sadighi@alumni.iut.ac.ir; mohamali@cc.iut.ac.ir
}

Received: 13 December 2018; Accepted: 15 February 2019; Available online: 30 May 2019

\begin{abstract}
The high exposure of areas in the vicinity of oil plants and refineries to crude oil and oil product contaminations and the problems they cause for the physical expansion of these facilities underscore the importance of stabilization of oil-contaminated soils. Soil stabilization with cost-effective stabilizing agents is widely regarded as a simple and fast way of limiting the impacts of such contaminations. For decades, cement and lime have been the standard binders for soil remediation and stabilization applications, but with the increasing awareness about their environmental impact and the notion of sustainable development in general, there is now a growing interest in the use of cleaner alternatives based on new technologies for this purpose. In recent years, alkali-activated binders have been the subject of much interest because of their high strength and durability and limited environmental impacts. The soil treatment solution investigated in this study is the use of slag, which is a steel production byproduct mostly consisting of calcium and magnesium alumina silicates, in combination with two activators, namely sodium hydroxide and sodium silicate. Direct shear tests were performed on the crude oil contaminated soil specimens in order to determine the best alkali-activated designs and the effect of exposure time, slag content, and treatment time on the outcomes. The test results showed that adding $10 \%$ slag, $1.15 \%$ sodium silicate, and $1.61 \%$ sodium hydroxide (all by dry weight of soil) to the crude oil contaminated soil improved its cohesion and friction angle by $70 \%$ and $50 \%$ respectively.
\end{abstract}

Keywords: Stabilization; Crude oil; Soil; Alkali-Activated Slag.

\section{Introduction}

Safety and cost-effectiveness are the two basic requirements of almost any engineering design. From an engineering perspective, the release of oil and oil-based contaminates exposes the nearby structures to severe safety risks associated with contamination-induced soil strength reduction. The fact that crude oil and oil product contaminations often occur near oil plants and refineries and this complicates the physical expansion of these facilities further highlight the need for serious attention to this problem.

Cement and lime have long served as standard stabilizers in soil stabilization applications. However, with the increased awareness about the environmental impacts and particularly the high carbon footprint of these materials, on the one hand, and the rising taxes on industrial waste disposal, on the other hand, recent years have seen growing research interest in alternative stabilizers obtained by the recycling of industrial by-products (IBPs) and preferably alumina silicate-based products [1]. For several years, alkali-actives binders, which basically consist of magnesium and calcium alumina silicates, have been the subject of much interest to researchers because of their high strength and durability and limited environmental pollution [2,3]. What distinguishes slag from other pozzolanic materials like metakaolin and fly ash is its high calcium $(\mathrm{CaO})$ content which makes it chemically similar to Portland cement. If you mix the crushed slag with water, the formation of thin hydrated layers containing $\mathrm{Ca}^{+2}$ and $\mathrm{SiO}_{2}$ raises the $\mathrm{pH}$ level to about 11. Since the presence of these hydrated layers at the surface of slag grains disrupts the hydration reaction, an appropriate activating agent should be added to the mixture to ensure the continuity of reactions. Alkali activators increase the $\mathrm{pH}$ of the liquid phase and prevent the formation of protective layers on the surface of slag grains, thereby allowing the glass phase to dissolve uninterrupted. The role of alkali activators is to break down the bonds in the glass phase of the slag so as to accelerate the dissolution of ionic components [4]. In this process, sodium hydroxide $(\mathrm{NaOH})$ can be used to greatly boost the solution alkalinity in order to allow the slag hydration reaction to continue. One can also use sodium silicate $\left(\mathrm{Na}_{2} \mathrm{SiO}_{3}\right)$ as a rich source of silica to increase the amount of hydrated calcium silicate gel produced in the process [4]. Notable among the earliest works on soil stabilization with IBP binders are the studies conducted by Al-Tabbaa and Evans (1998 and 1999) in the United Kingdom. These researchers measured the unconfined compressive strength (UCS) of the soils mixed with different percentages (by weight) of stabilizer after 28 days of treatment. These works reported a UCS of 350-1100kPa, low permeability, and a pH between 6.5 and 10.5 for the tested mixtures [5, 6]. In a study by Ahenberg (2007), different 
combinations of stabilizers including lime + type II cement, type II cement + PFA, type II cement + GGBS, and lime + GGBS, which were mixed at 50-50 ratio, were used for soil stabilization. This study reported that lime has a greater impact on the activation of industrial waste than cement [7]. Yadu et al. (2013) performed a series of uniaxial tests on soft soils stabilized with different amounts of slag (0-12\% by dry weight of soil). From the test results, this study concluded that using slag causes a sharp increase in the uniaxial strength [8].

In 2015, Moon et al. studied the stabilization of $\mathrm{As}^{-}, \mathrm{Pb}^{-}$, and $\mathrm{Cu}^{-}$contaminated soils using steel slag and found that it increases the strength of contaminated soils [9]. But, one of the seminal works regarding the geotechnical properties of contaminated soils is a research by Lekmine (1991), where several experiments were conducted to investigate the mechanical properties of different soils contaminated with hydrocarbon compounds. The contaminants considered in that study were kerosene and gas oil. This research reported that oil contamination reduces the soil strength, but this strength reduction reduces with time [10].

Al Sand and Ismael (1995) conducted a research program to measure the amount of oil pollution from the second Gulf War in the sand surrounding the lakes created to accumulate floating oil patches. To determine the effect of oil pollution on the engineering characteristics of Kuwaiti beach sands contaminated with oil. The results of these experiments showed that the oil pollution increased up to 4 percent enhanced compatibility while at higher amount of contamination the soil compressibility decreased [11].

In 2007, Khamehchiyan et al. have made an extensive research on the oil polluted soils from the Persian Gulf coasts. It was found that, in general, oil contamination reduces the permeability and strength in all specimens [12].

Abousnina et al. (2015) suggested the use of oil-contaminated sand as a road construction material which seems to be a cost-effective solution to minimize adverse environmental impacts. In this context, the effect of oil pollution on mechanical properties of sand was investigated. The results showed that with an increase in contamination up to $1 \%$, the soil shear strength increases while it experiences some reduction at greater percentages of contamination [13].

In a study by Al-Adili et al. (2017), it was found that crude oil increases the liquid limit, specific gravity, and the amount of moisture needed to reach the maximum dry density. Further, crude oil was reported to have a significant impact on the internal friction of sandy soil. This study also reported that exposure to oil increases the soil consolidation and swelling and decreases its porosity and hydraulic conductivity [14].

The present study is based on the idea that the hydration reactions that occur following the addition of slag and alkali solution produce a $\mathrm{C}-\mathrm{S}-\mathrm{H}$ gel, which acts as a binder that can significantly contribute to the stabilization of crude oil contaminated soils and the improvement of soil strength. This gel, which is known to increase the density of microstructures [15], can be conveniently created with alkali-activated slag to serve as the third generation of cementitious binders after lime and Portland cement [16].

\section{Materials and methods}

\subsection{Materials}

The soil samples used in this research were collected from the Isfahan refinery site from a depth of 0-3 meters. In order to identify the soil, the size distribution of soil particles was first determined according to ASTM D 42263. As seen from Fig.1, the fine fraction of the soil is about 10\%. Thus both plastic properties and gradation coefficients are required for the soil classification. The soil specifications are presented in Table 1. Also, the specifications of crude oil used in Isfahan refinery, as the source of soil pollution, are summarized in Table 2.

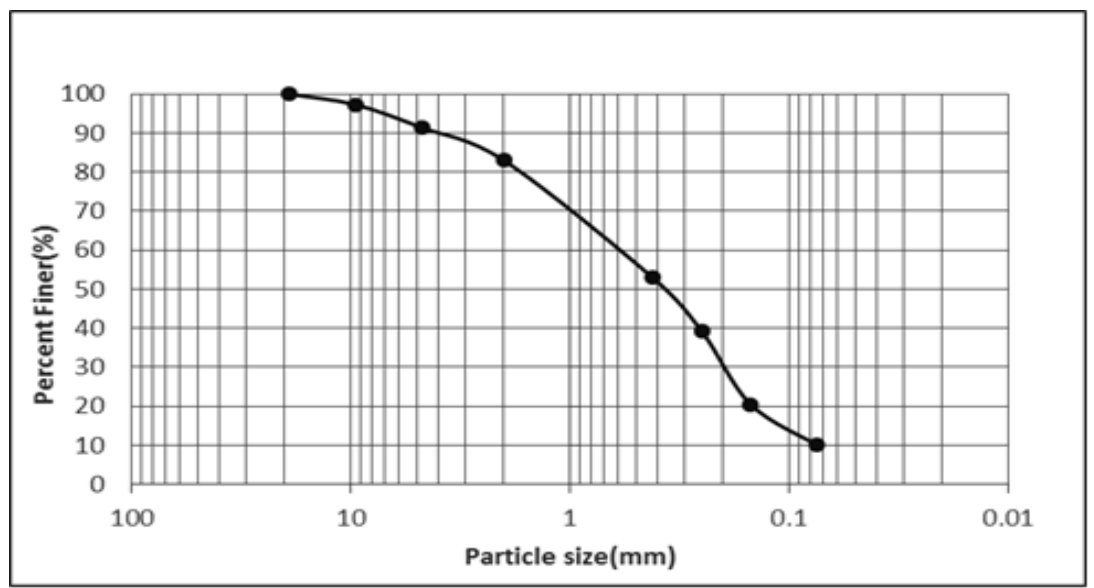

Fig.1.Particle Size Distribution of the Testing Soil 
Table 1. Soil Specifications

\begin{tabular}{ll}
\hline Gradation Coefficients & $\mathrm{Cu}=8, \& \mathrm{Cc}=0.89$ \\
\hline Liquid Limit & 31 \\
Plastic limit & 20 \\
Plastic Index & 11 \\
Specific Gravity (Gs) & 2.8 \\
Soil Classification (USCS) & $\mathrm{SP}-\mathrm{SC}$ \\
\hline
\end{tabular}

Table 2. Physical-chemical characteristics of crude oil as a soil contaminant

\begin{tabular}{lll}
\hline Test Method & Result & Characteristics \\
\hline ASTM D4052 & .8556 & Special Weight in15.560C \\
ASTM D4052 & 33.88 & API \\
ASTM D95 & TRACE<.05 & Water percentage \\
ASTM D323 & 8.9 & R.V.P(PSI) \\
ASTM D3240 & 9.2 & (Salt percentage) R.T.B \\
ASTM D189 & 2.99 & Carbon remaining (WT \%) \\
IP143 & 1.1 & Asphaltene (WT \%) \\
BP237 & 4.76 & Wax (WT \%) \\
UOP 46 & 2.2 & Dielectric constant \\
ASTM D97 & -18 & C ${ }^{\text {Point of flood) }}$ \\
ASTM D445 & 14.92 & Viscosity (At 10 $0^{\circ}$ ) \\
\hline
\end{tabular}

\subsection{Slag}

The slag used in this study was the byproduct of the blast furnace of the Isfahan smelting plan and was ground by the Madaen Cement Factory. This slag had a specific gravity of $2.85 \mathrm{gr} / \mathrm{cm} 2$ and a fineness of $4.8 \mathrm{~cm} 2 / \mathrm{g}$. The chemical composition of the slag is given in Table 3.

Table 3. Chemical composition of the slag used

\begin{tabular}{llllllll}
\hline $\mathrm{CaO}$ & $\mathrm{SiO}_{2}$ & $\mathrm{Al}_{2} \mathrm{O}_{3}$ & $\mathrm{Fe}_{2} \mathrm{O}_{3}$ & $\mathrm{MgO}$ & $\mathrm{SO}_{3}$ & $\mathrm{~K}_{2} \mathrm{O}$ & $\mathrm{Na}_{2} \mathrm{O}$ \\
\hline 34.8 & 37.5 & 6.4 & .51 & 8.6 & 2.49 & .9 & .38 \\
\hline
\end{tabular}

\subsection{Sodium silicate $\left(\mathrm{Na}_{2} \mathrm{SiO}_{3}\right)$}

Sodium silicate, also known as water glass, is one of the compounds typically used to increase alkalinity for slag activation. The specific gravity of the sodium silicate solution used in this study was approximately 1500 $\mathrm{kg} / \mathrm{m}^{3}$. The chemical composition of this sodium silicate is given in Table 4 .

Table 4. Chemical composition of the silicates

\begin{tabular}{lll}
\hline $\mathrm{H}_{2} \mathrm{O}$ & $\mathrm{Na}_{2} \mathrm{O}$ & $\mathrm{SiO}_{2}$ \\
\hline 48 & 14 & 38 \\
\hline
\end{tabular}

\subsection{Methods}

According to the field reports, the range of crude oil pollution at the Isfahan Refinery site is estimated to be between $4 \%$ and $8 \%$. For having more control on the soil conditions, clean soil samples from the refinery protected site were contaminated with crude oil at 4 and $8 \%$ of the soil dry weight. The required amount of soil for direct shear tests was also mixed with desired amount of crude oil. It should be noted that at least 2 days should elapse to allow soil particles to absorb the added oil (transmitting from free-flow phase to absorbed phase). To achieve the desired state, the polluted samples were stored within sealed two layers plastic bags[17].

The mixed method in this study is to calculate and weigh some of the impurities in crude oil, slag and alkaline solution with specified concentrations, then dry soil and slag are mixed manually and blended for ten minutes to achieve homogeneous mix. The solution is then added to the mixture and mixed well for 10 minutes. Finally, the homogeneous mixture was poured into a direct shear sample and, after one to two hours, it was removed from the mold and placed in sealed plastic bags, and the samples were exposed to laboratory temperature for curing 2,7 , 14,21 days and then subjected to direct shear. 


\section{Results and discussion}

\subsection{Effect of crude oil on geotechnical properties}

Figures 2 and 3 show the changes of soil cohesion and friction angle as it remained exposed to $4 \%$ and $8 \%$ oil contamination.

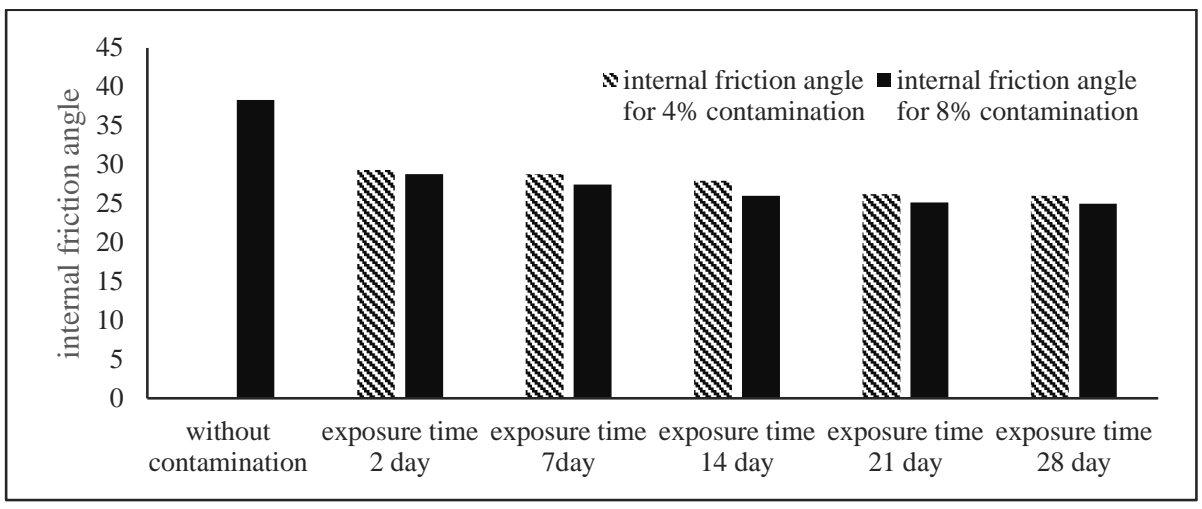

Figure 2. Changes of soil friction angle versus exposure time

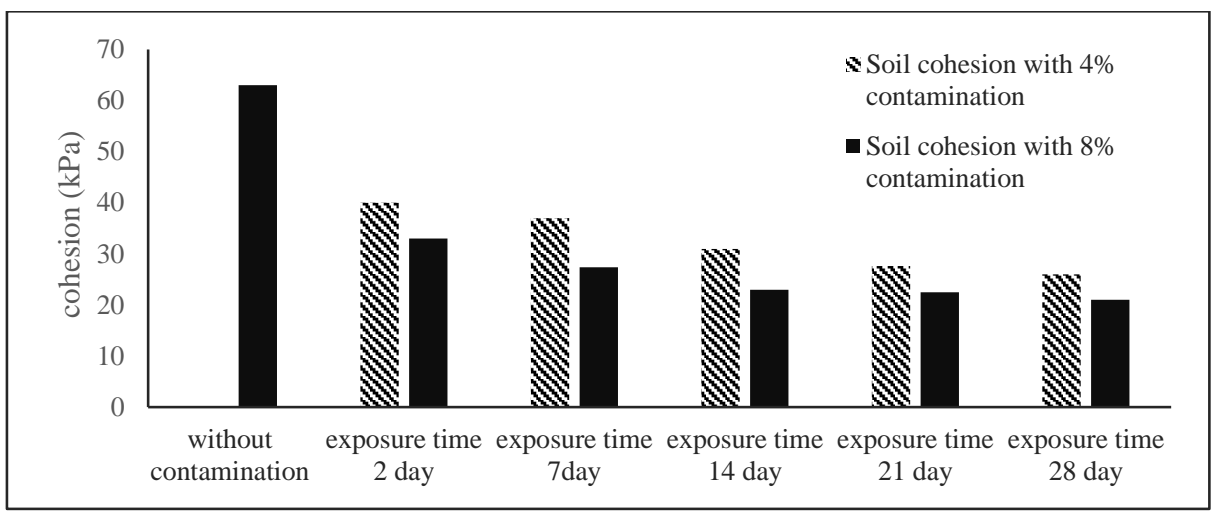

Figure 3. Changes of soil cohesion versus exposure time

The decreasing trend of the friction angle in Figure 2 can be attributed to the reduction of effective friction between soil grains and the closer packing of grains, as well as the lubricating effect of oil. The results show that with the prolongation of exposure, the friction angle decreased at a slower pace. Eventually, oil absorption by the soil became almost constant after about 21 days.

As shown in Figure 3, the test results indicate that the longer the exposure, the lower becomes the soil cohesion. This is because the presence of oil facilitates the agglomeration of fine soil particles, which leads to a decrease in the specific surface of the soil, and in turn, results in less bonding between soil particles and thus decreased cohesion. With the passage of time and the prolongation of soil-oil interaction, the magnitude of cohesion reduction increases. As can be seen, this cohesion reduction is higher in $8 \%$ contamination than in $4 \%$ contamination.

The changes in cohesion and friction angle with the amount of contamination are illustrated in Figures 4 and 5. It can be seen that at $2 \%$ (by dry weight of soil) contamination, soil actually has a slightly increased cohesion, which is due to lubrication between soil particles. In the case of friction angle, the presence of oil contamination in any amount reduces this angle. However, the rate of friction angle reduction decreases as the magnitude of contamination increases. This is because the effect of oil on the interlocking of soil grains and their ability to slide over each other peaks at 8\% contamination (more oil does not strengthen this effect). These results are consistent with the findings of Abousnina et al. [15].

\subsection{Results of direct shear test on slag-treated contaminated soil specimens}

First, to determine the optimum slag content for strength improvement, the direct shear test was conducted on a series of specimens made with the following specifications: oil contamination of $8 \%$, slag contents of 5,10 and $15 \%$, sodium silicate content of $1.5 \%$, and sodium hydroxide content of $1.61 \%$ (all percentages are by dry weight of soil). As shown in Figure 6, the test results showed that soil strength increases with the amount of slag added (the specimen with $15 \%$ slag content had the highest strength). But, given the negligible difference between the 
soil strengths attained with the slag contents of $10 \%$ and $15 \%$ (see Figure 6), the lowest among these two. For this reason $10 \%$, was selected to achieve better cost-effectiveness. It is notable that this figure is consistent with the reports of Yadu et al. [8].

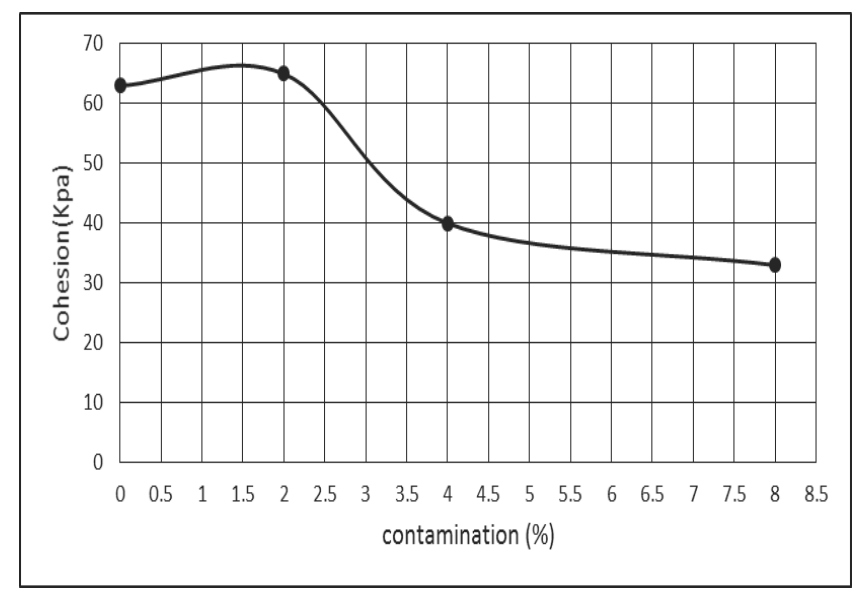

Figure 4. Changes of soil cohesion versus contamination content

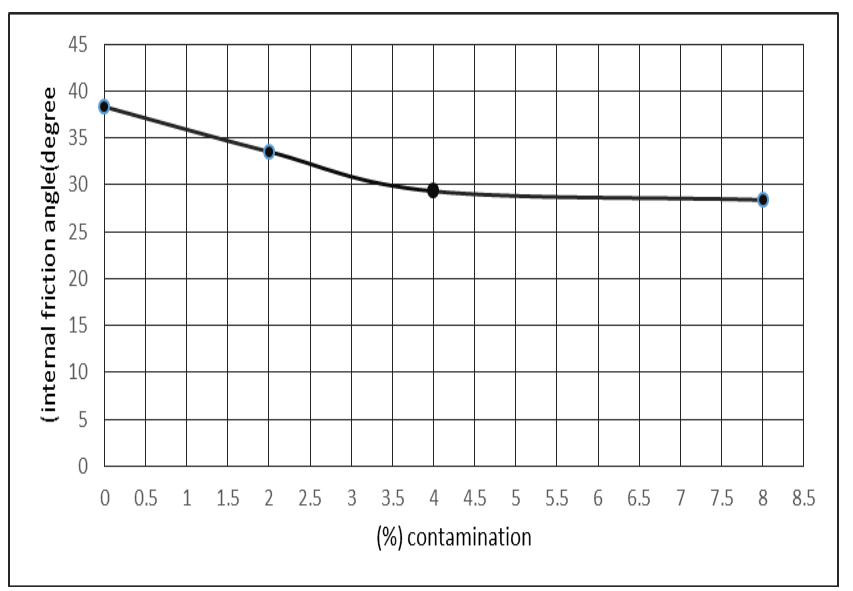

Figure 5. Changes of soil friction angle versus contamination content

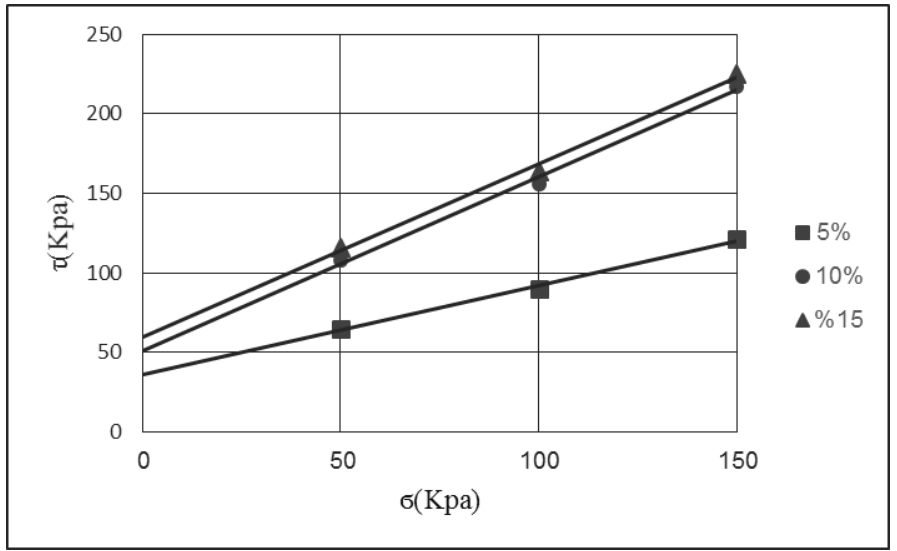

Figure 6. Mohr-Coulomb diagram of the soil treated with different amounts of pozzolanic slag

When mixed with water alone, the slag decomposes into fine particles, but the formation of a layer of $\mathrm{Ca}^{2+}$ prevents further reactions. Raising the mixture $\mathrm{pH}$ can remove this protective layer and let the reaction continue. Thus, as with the slag cement, the purpose of activators (alkali) in the alkali-activated slag is to provide the mixture with enough $\mathrm{OH}^{-}$ions to ensure that reactions continue as intended. The coating formed on the surface of slag grains after mixing with water prevents hydration in the subsequent steps. Hence, an alkali solution is needed to 
break this coating. In slag cement, this task is done by $\mathrm{Ca}(\mathrm{OH})_{2}$ produced by the hydration of cement, but at higher slag-cement replacement ratios, there will not be enough $\mathrm{Ca}(\mathrm{OH})_{2}$ and so an external source of alkali will be needed to assist this process. As with cement hydration, the final product of this reaction is the C-S-H gel, but the major difference is the speed and intensity of the reaction. In the presence of $\mathrm{Ca}(\mathrm{OH})_{2}$, slag can also trigger pozzolanic reactions. In general, sodium hydroxide increases the mixture $\mathrm{pH}$, which facilitates rapid slag degradation, while sodium silicate acts as a source of $\mathrm{Si}$, which increases the production of $\mathrm{C}-\mathrm{S}-\mathrm{H}$ gel and creates a denser microstructure. Based on previous experiences [8], the following three designs were used to determine the best activator for the stabilization of soils exposed to $8 \%$ crude oil contamination for two days (all percentages are by dry weight of soil):

1) Design $1=10 \%$ slag $+1.62 \%$ sodium hydroxide $+1.50 \%$ sodium silicate

2) Design $2=10 \%$ slag $+1.50 \%$ sodium hydroxide $+1.85 \%$ sodium silicate

3) Design $3=10 \%$ slag $+1.38 \%$ sodium hydroxide $+2.10 \%$ sodium silicate

The results of direct shear tests conducted on the contaminated soil specimens treated with the aforementioned designs are illustrated in Figure 7.

As shown in Figure 7, soil strength increased with the amount of sodium silicate added. This is because, in the absence of enough sodium silicate, the reaction with the slag cannot be completed properly, which leads to a lower soil strength. An increase in the sodium silicate content means a greater amount of Si is available for reaction, which translates into increased production of C-S-H gel by the slag hydration and therefore increased soil strength improvement. According to the results obtained by the above designs, Design $3(10 \%$ slag $+1.50 \%$ sodium hydroxide $+2.10 \%$ sodium silicate) was chosen as the best design for the treatment of crude oil-contaminated soil for strength improvement.

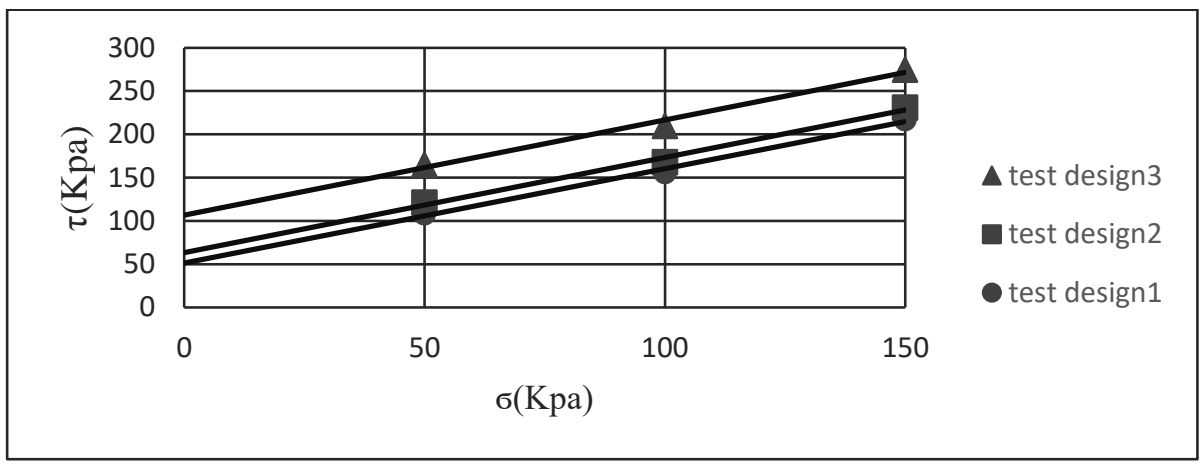

Figure 7. Mohr-Coulomb diagram of the soil treated with 3 Design

\subsection{Effect of exposure time and treatment time on the strength of contaminated soil}

The results of the tests conducted on the soil specimens exposed to $8 \%$ oil contamination (by dry weight of soil) for 2, 7, 14, 21 and 28 days show that as the exposure time increased, soil strength decreased. However, since there was not much difference between the result pertaining to 21 days and 28 days of contamination, the maximum exposure time was capped to 21 days. The results of the direct shear test conducted on the soil specimens exposed to $8 \%$ contamination for different times after treatment with the optimal slag content $(10 \%)$ and the alkali mixture of Design 3 are presented in Figures 8 and 9.

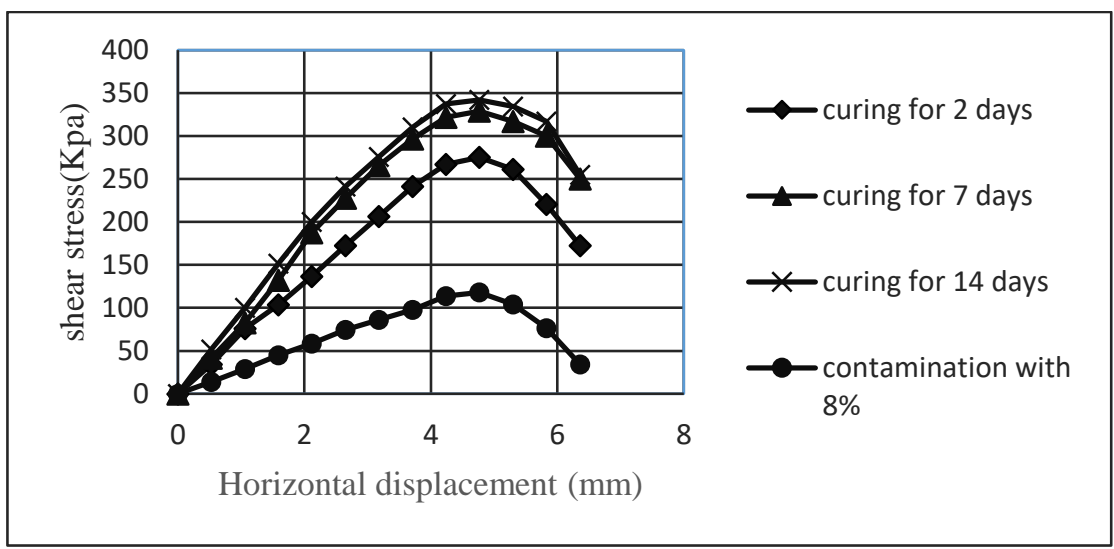

Fig. 8 Shear stress versus shear displacement for vertical stress of $150 \mathrm{kPa}$ 


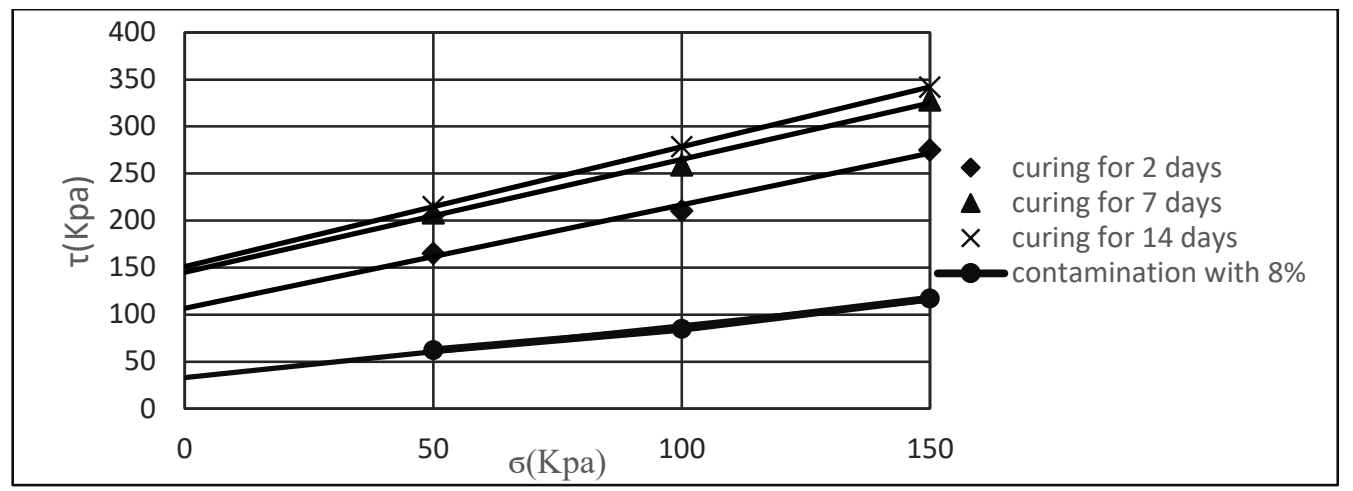

Figure 9. Mohr coulomb with curing duration

In these figures, it can be seen that soil strength increases with the slag treatment time; a result that can be attributed to the increasing amount of $\mathrm{C}-\mathrm{S}-\mathrm{H}$ gel produced over time.

The changes in the internal friction angle and cohesion of the soil specimens exposed to $8 \%$ contamination for 1, 2, and 3 weeks are illustrated in Figures 10 and 11.

These figures show that as the exposure time increases, so does the treatment time needed to reach a certain level of soil stabilization. It should be noted that there is not much difference between the friction angles resulted from 7 days and 14 days of exposure to contamination, but longer exposures increase the treatment time required to reach the highest strength.

From these results, it can be deduced that there is a direct relationship between the exposure time and the treatment time, which means the longer the soil is exposed to oil, the longer it should be treated to reach its maximum strength.
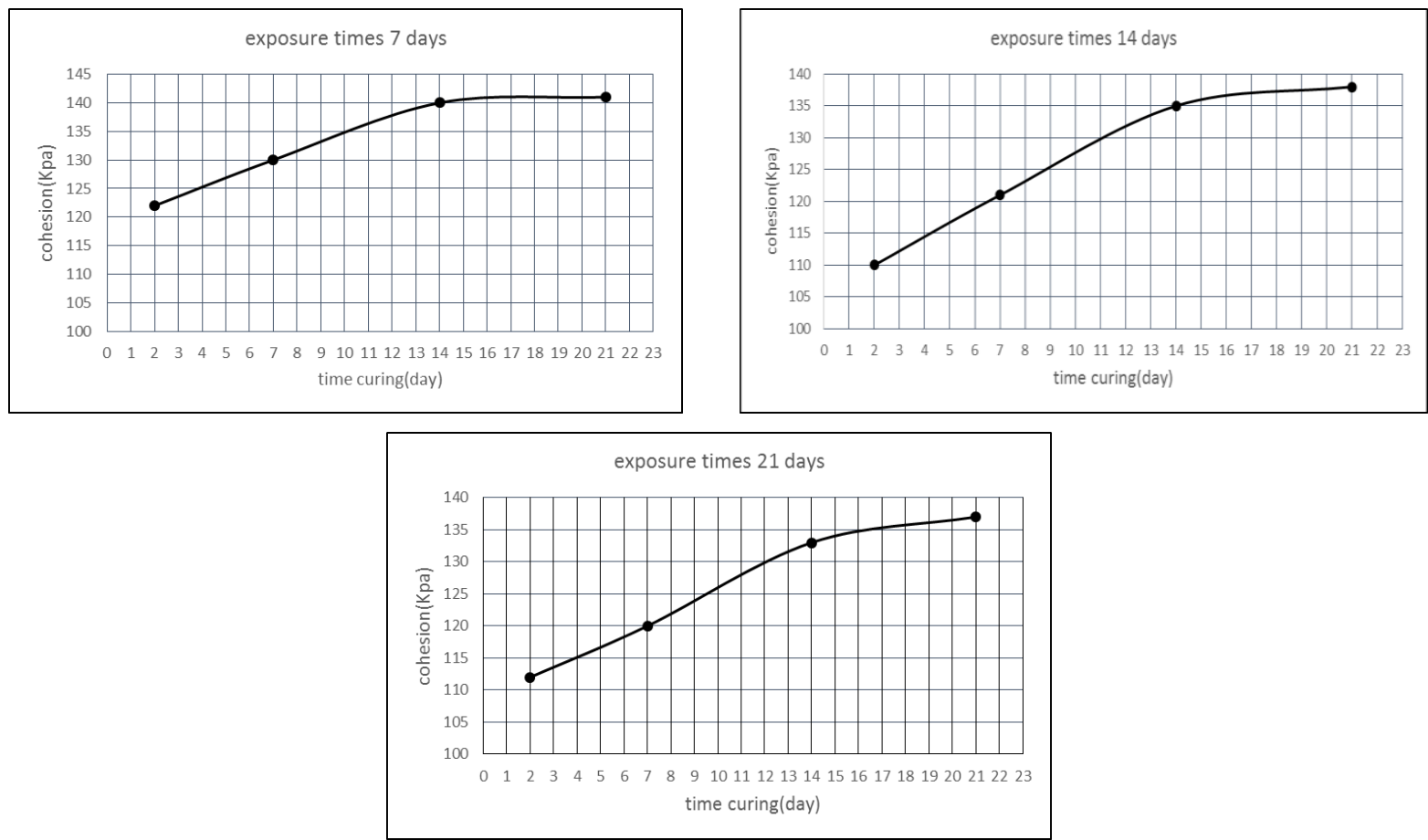

Figure 10. Cohesion the soil specimens at different exposure times and treatment times

\section{Conclusion}

In the first set of tests conducted in this study, the soil specimens with 2, 7, 14, 21, and 28 days of exposure to $8 \%$ (by dry weight of soil) crude oil contamination were subjected to direct shear testing. The test results obtained for a soil with an internal friction angle of 38 degrees and cohesion of $63 \mathrm{kPa}$ (in the clean state) showed that with the prolongation of exposure to $8 \%$ contamination, the internal friction angle and cohesion decreased, respectively, from 29 degrees to 25 degrees and from $33 \mathrm{kPa}$ to $21 \mathrm{kPa}$. However, the changes observed between the $21 \mathrm{st}$ day 
and the 28th day were very limited. In the next set of experiments, the contaminated soil specimens were mixed with a combination of slag $(5,7.5,10,12.5$ and 15\%) and two alkaline activating agents, namely sodium silicate $(1.15 \%)$ and sodium hydroxide $(1.61 \%)$ and were tested after two days of treatment. A summary of the results obtained from these tests is presented below:

Soil strength increased with the amount of slag used for treatment, but since the improvements observed after raising the slag content beyond $10 \%$ were practically insignificant, this figure was chosen as the optimum slag content.

The addition of $10 \%$ slag to the soils with $4 \%$ and $8 \%$ contamination improved their cohesion by $65 \%$ and 80 $\%$, respectively.

The addition of $10 \%$ slag to the soils with $4 \%$ and $8 \%$ contamination improved their friction angle by $50 \%$ and $60 \%$, respectively.

The addition of alkaline solution, specifically sodium silicate, to the slag led to better strength improvement, probably because sodium silicate can serve as a source of silica and therefore as a catalyst for strength enhancing reactions.

There is a direct relationship between the time of exposure to contamination and the treatment time. In other words, the longer the soil is exposed to oil, the longer it should be treated to reach its maximum strength.
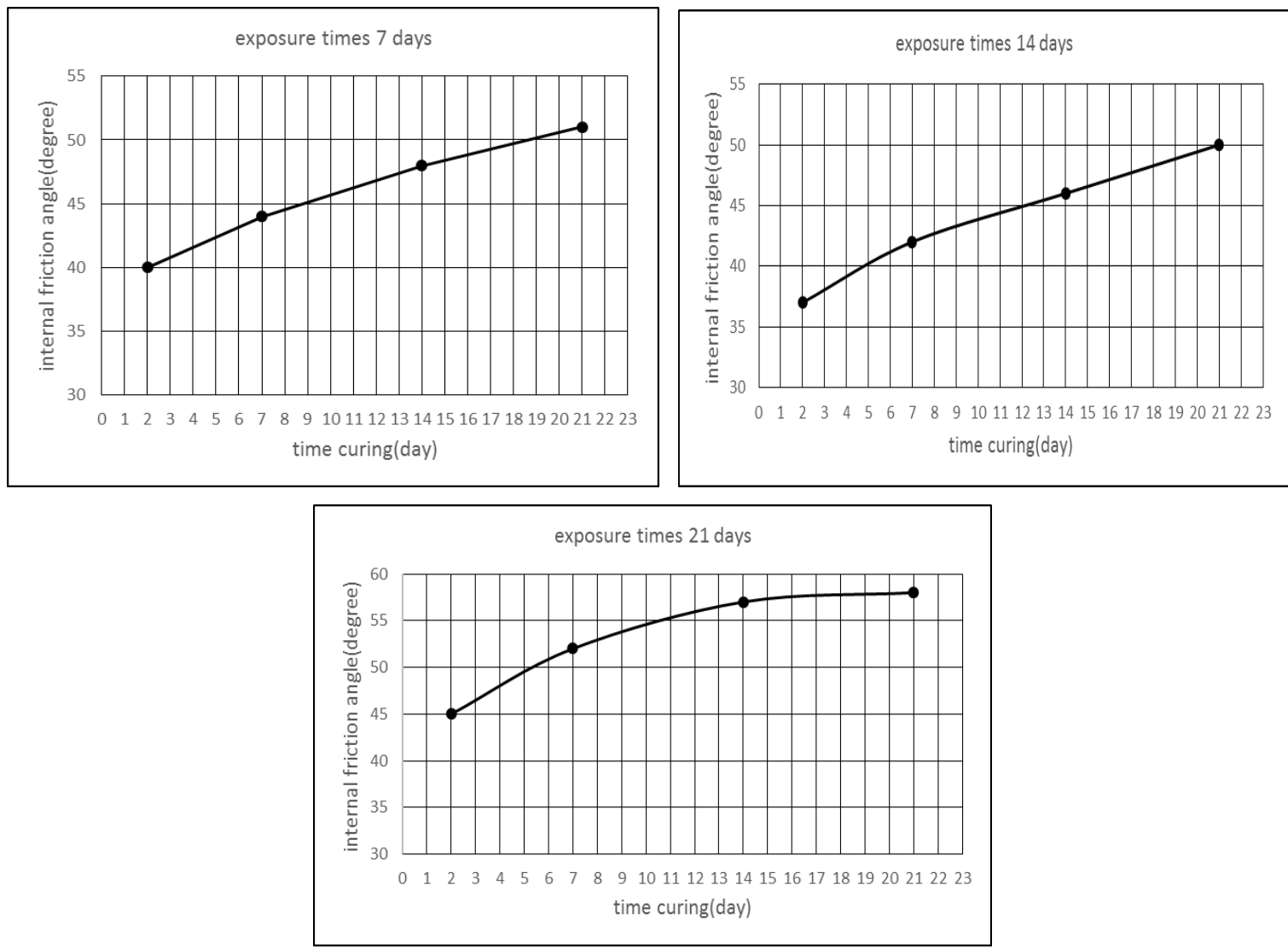

Fig. 11. Friction angle of the soil specimens at different exposure times and treatment times

\section{References}

[1] Sargent P. The development of alkali-activated mixtures for soil stabilisation. In: Handbook of AlkaliActivated Cements, Mortars and Concretes. Woodhead Publishing; 2015. p. 555-604.

[2] Juenger MC, Winnefeld F, Provis JL, Ideker JH. Advances in alternative cementitious binders. Cement and Concrete Research. 2011;41(12):1232-1243.

[3] Davidovits J. Global warming impact on the cement and aggregates industries. World Resource Review. 1994;6(2):263-278.

[4] Adam A. Strength and durability properties of alkali activated slag and fly ash-based geopolymer concrete. RMIT University Melbourne, Australia; 2009 
[5] Davidson LK, Demirel T, Handy RL. Soil pulveration and lime migration in soil-lime stabilization. Highway Research Record. 1965(92).

[6] Mohebi R, Behfarnia K, Shojaei M. Abrasion resistance of alkali-activated slag concrete designed by Taguchi method. Construction and Building Materials. 2015;98:792-798.

[7] Al-Tabbaa A, Evans CW. Pilot in situ auger mixing treatment of a contaminated site. Part 1: Treatability study. Geotechnical Engineering. 1998;131(1): 52-59.

[8] Al-Tabbaa A, Evans CW. Laboratory-scale soil mixing of a contaminated site. Journal of Ground Improvement. 1999;3(3):119-134.

[9] Åhnberg H. On yield stresses and the influence of curing stresses on stress paths and strength measured in triaxial testing of stabilized soils. Canadian Geotechnical Journal. 2007;44(1):54-66.

[10] Yadu L, Tripathi RK. Effects of granulated blast furnace slag in the engineering behaviour of stabilized soft soil. Procedia Engineering. 2013;51:125-131.

[11] Moon DH, Cheong KH, Koutsospyros A, Chang YY, Hyun S, Ok YS, Park JH. Assessment of waste oyster shells and coal mine drainage sludge for the stabilization of As-, $\mathrm{Pb}-$, and Cu-contaminated soil. Environmental Science and Pollution Research. 2016;23(3):2362-2370.

[12] Lekmine DE. Effect of petroleum hydrocarbons on the shear strength and comperessability of soils. [PhD thesis]. Stevens Institute of Technology, N.J.; 1991.p.441.

[13] Al-Sanad HA, Eid WK, Ismael NF. Geotechnical properties of oil-contaminated Kuwaiti sand. Journal of Geotechnical Engineering. 1995;121(5):407-412.

[14] Khamehchiyan M, Charkhabi AH, Tajik M. Effects of crude oil contamination on geotechnical properties of clayey and sandy soils. Engineering Geology. 2007;89(3-4):220-229.

[15] Abousnina RM, Manalo A, Shiau J, Lokuge W. Effects of light crude oil contamination on the physical and mechanical properties of fine sand. Soil and Sediment Contamination: An International Journal. 2015;24(8):833-845.

[16] Al-Adili A, Alsoudany KY, Shakir A. Investigation of crude oil pollution effect on stiffness characteristics of sandy and gypseous soil. Soil Mechanics and Foundation Engineering. 2017; 54(4):276-282.

[17] Evgin E, Das B. Mechanical behavior of an oil contaminated sand. Environmental Geotechnology, Usmen \& Acar (eds). , Rotterdam: Balkema; 1992

(C) 2019 by the author(s). This work is licensed under a Creative Commons Attribution 4.0 International License (http://creativecommons.org/licenses/by/4.0/). Authors retain copyright of their work, with first publication rights granted to Tech Reviews Ltd. 